\title{
THE PERFORMANCE ANALYSIS OF ULTRA HIGH SPEED PM TYPE SYNCHRONOUS MOTOR-GENERATOR FOR MICRO TURBINE
}

\author{
DO-KWAN HONG \\ Electric Motor Research Center, Korea Electrotechnology Research Institute, 28-1 Sungju-dong, Changwon, \\ KyungNam, 641-120, Korea \\ dkhong@keri.re.k \\ BYUNG-CHUL WOO \\ Electric Motor Research Center, Korea Electrotechnology Research Institute, 28-1 Sungju-dong, Changwon, \\ KyungNam, 641-120, Korea \\ bcwoo@keri.re.kr \\ YEON-HO JEONG \\ Electric Motor Research Center, Korea Electrotechnology Research Institute, 28-1 Sungju-dong, Changwon, \\ KyungNam, 641-120, Korea \\ yhjeong@keri.re.kr

\section{DAE-HYUN KOO} \\ Electric Motor Research Center, Korea Electrotechnology Research Institute, 28-1 Sungju-dong, Changwon, \\ KyungNam, 641-120, Korea \\ dhk371@keri.re.kr

\section{YUN-HYUN CHO} \\ Department of Electrical Engineering, Dong-A University, 840 Hadan2-dong, \\ Busan, 604-714, Korea \\ yhcho@dau.ac.kr
}

\begin{abstract}
This paper deals with loss analysis, structural, thermal-fluid and rotordynamics (critical speed and unbalance) which need in developing the motor-generator. This machine has designed of a generator of $800 \mathrm{~W}, 400 \mathrm{krpm}$ and a starter of $400 \mathrm{~W}, 200 \mathrm{krpm}$. The generated losses of motor-generator are derived by magnetic analysis. Thermal-fluid analysis is performed using loss analysis result. The critical speed is extracted by Campbell diagram. Unbalance vibration response analysis enable to predict the expected vibration amplitude by unbalance. The motor-generator is well-developed using the applied several techniques of analysis.
\end{abstract}

Keywords: Stator loss; Rotor loss; Motor-Generator; Critical Speed; Unbalance Analysis; ThermalFluid analysis; Shrink fit. 


\section{Introduction}

If ultra high speed motor-generator is applied to micro gas turbine, the system can be simplified. An electro-mechanical system can be made much smaller and lighter at the same power level by increasing its operating speed. The permanent magnet excited synchronous generator has many advantages as compared with existing synchronous generator, but it has been applied in limited field. However, the many interest and development is being done as power electronics and control method develop recently. The operating method of motor-generator for micro turbine is operated as synchronous motor in transient performance and also is acted as acceleration until turbine reaches in a certain speed [1],[2].

Finally, ultra high speed motor-generator which is rated a generator of $800 \mathrm{~W}, 400$ $\mathrm{krpm}$ and a starter of $400 \mathrm{~W}, 200 \mathrm{krpm}$ is well-developed using design, several techniques of analysis and manufactural technique. Fig. 1 shows prototype and parts. Table 1 shows proposed 3-phase Permanent Magnet Synchronous Motor (PMSM) dimension. Fig. 2 shows performance curve of motor-generator using EMCNM.

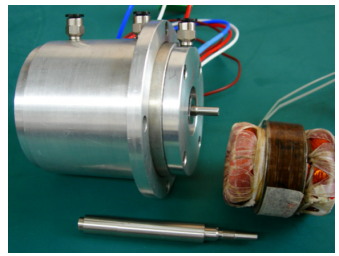

(a) Prototype

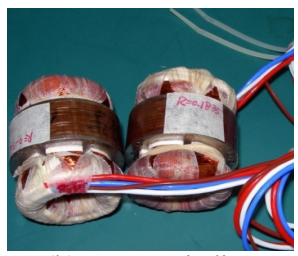

(b) Stator, winding

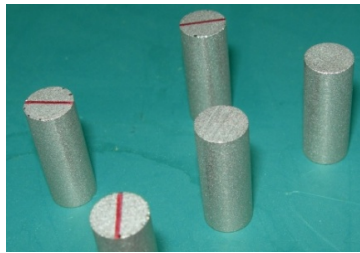

(c) Permanent magnet $\left(\mathrm{Sm}_{2} \mathrm{Co}_{17}\right)$

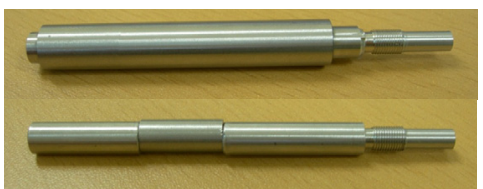

(d) Rotor(sleeve and stub shaft)

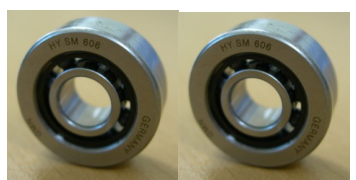

(e) Ceramic ball bearing for high speed

Fig. 1. The developed Permanent Magnet Synchronous Motor (PMSM)

Table 1. The specification of the developed motor-generator

\begin{tabular}{|c|c|c|c|}
\hline Mode & Item & Value & Note \\
\hline \multirow{11}{*}{ Generating } & Rated power (W) & 800 & \multirow[t]{5}{*}{ AC load } \\
\hline & Rated speed (rpm) & 400,000 & \\
\hline & Rated voltage (V) & 110 & \\
\hline & Rated current (A) & 4.20 & \\
\hline & Current density $\left(\mathrm{A} / \mathrm{mm}^{2}\right)$ & 6.96 & \\
\hline & Efficiency $(\%)$ & 94 & Consider loss \\
\hline & Phase resistance $(\mathrm{m} \Omega)$ & 4.385 & Consider $150{ }^{\circ} \mathrm{C}$ \\
\hline & Synchronous inductance $(\mu \mathrm{H})$ & 189.636 & Consider DC \\
\hline & Flux linkage (Vs/rad) & 0.002491 & Consider $150^{\circ} \mathrm{C}$ \\
\hline & BEMF(line) (mVrms/rpm) & 0.31949 & Consider $150^{\circ} \mathrm{C}$ \\
\hline & Torque constant $(\mathrm{Nm} / \mathrm{A})$ & 0.005 & Consider $150^{\circ} \mathrm{C}$ \\
\hline \multirow{4}{*}{ Motoring } & Rated power (W) & 400 & \\
\hline & Rated speed (rpm) & 200,000 & \\
\hline & Rated voltage (V) & 72.3 & \\
\hline & Rated current (A) & 3.8 & \\
\hline
\end{tabular}




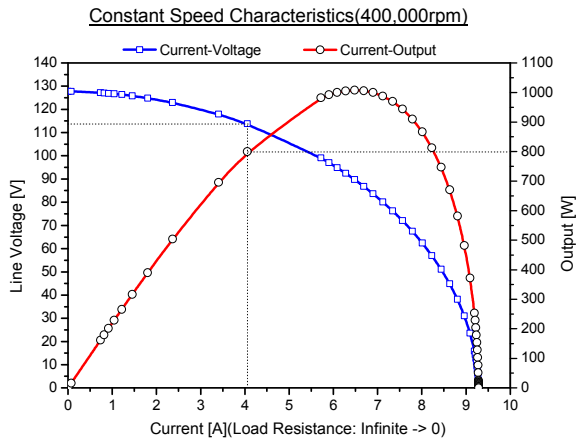

(a) Constant speed

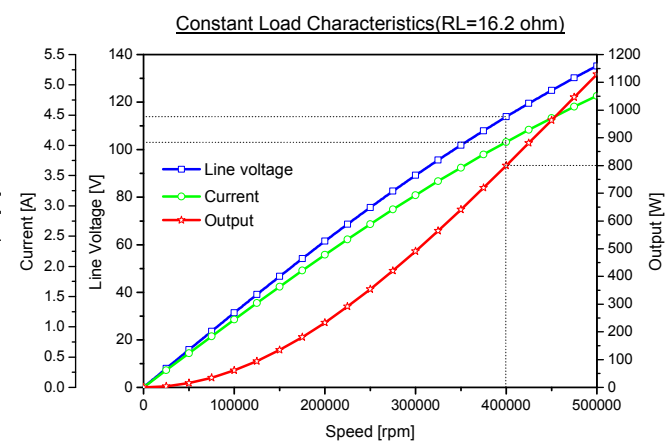

(b) Constant load

Fig. 2. Performance curve of motor-generator using Equivalent Magnetic Circuit Network Method (EMCNM).

\section{Stator loss}

Generally, stator losses can be divided into core loss and copper loss. Core loss which is generated in the laminated core is calculated as a constant of maximum flux density $\left(B_{m}\right)$ by Steinmetz equation. In case of core losses, the total losses are commonly expressed by (1) for sinusoidally varying magnetic flux density $\mathrm{B}$ with frequency $\mathrm{f}$ and they are divided into hysteresis loss and eddy current loss. Each of losses is calculated by (1) [3],[4].

$$
P_{\text {core }}=P_{h}+P_{e}+P_{a}=k_{h} B_{m}{ }^{n} f+k_{e} B_{m}{ }^{2} f^{2}+k_{a} B_{m}{ }^{1.5} f^{1.5}
$$

Where $P_{h}, P_{e}$ and $P_{a}$ is shown hysteresis loss, eddy current loss and strange eddy current loss. $k_{h}, k_{e}$ and $k_{a}$ is shown hysteresis loss coefficient, eddy current loss coefficient and strange eddy current loss coefficient. $\mathrm{n}$ is Steinmetz coefficient in the range 1.5 to 2.5

Core loss as a function of frequency and flux density is increased as a proportion and square in proportion to frequency. Fig. 3 shows core loss distribution and flux density distribution. The generated maximum flux density is $1.6(\mathrm{~T})$ in slot teeth.

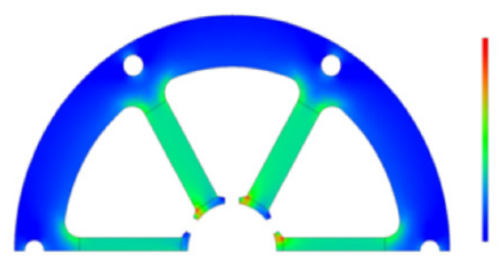

(a) Core loss distribution

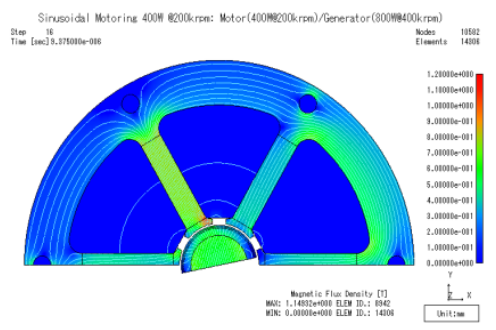

(b) Flux density distribution

Fig. 3. Core loss and flux density distribution

\section{Rotor loss}

Rotor loss is generated by eddy current loss in permanent magnet and sleeve with electrically conductive in Fig. 4. Rotor is heated by rotor loss because of thermal radiation difficulty although rotor loss is a small amount compared to stator loss. Also, thermal problem easily leads to demagnetization of permanent magnet. 


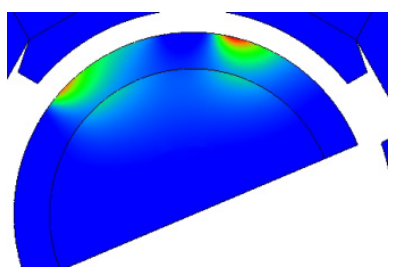

\begin{tabular}{ccc}
\hline Load & PM loss (W) & Sleeve loss (W) \\
\hline AC & 0.261 & 3.43 \\
DC & 1.312 & 4.831 \\
\hline
\end{tabular}

Fig. 4. Eddy current loss of rotor (PM and Sleeve)

\section{Shrink fit analysis according to interference}

It is necessary for structural analysis of rotor to select sleeve thickness in ultra high speed. The PM condition (compression or tensile) of shrink-fitted rotor should be checked. The shrink-fitted PM should be always in a state of compression in ultra high speed because of tensile condition is very weak. Maximum equivalent stress increases as a growing sleeve thickness. Fig. 5 shows von-Mises stress distribution in interference $0.003 \mathrm{~mm}$ for shrink fit (operating condition : 200,000 rpm, $210^{\circ} \mathrm{C}$ ). Inconel which has yield stress, $1100 \mathrm{MPa}$ is used for sleeve material.

The generated maximum von-Mises stress is $114.85 \mathrm{MPa}$ in case of sleeve thickness $0.8 \mathrm{~mm}$ and interference $0.003 \mathrm{~mm}$. The safety factor is $9.58(=1100 / 114.85)$. The PM is in a state of compression according to sleeve thickness [1].
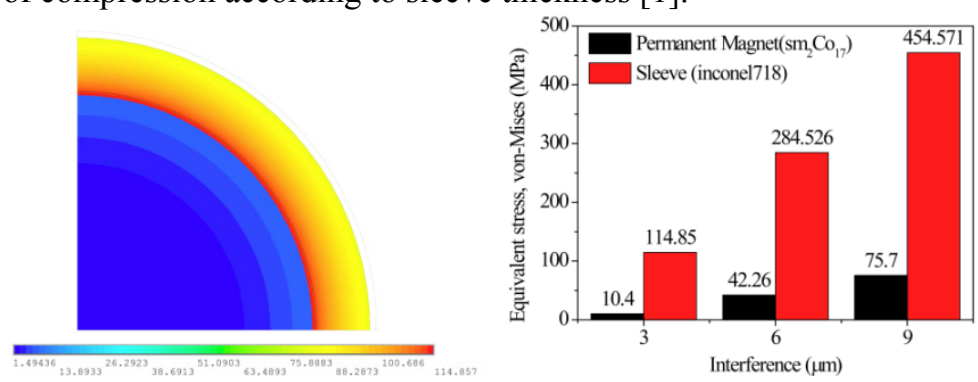

Fig. 5. von-Mises stress $\left(\sigma_{\text {eqv }}\right)$ distribution $\left(200 \mathrm{krpm}, 210^{\circ} \mathrm{C}\right)$

The von Mises criterion is also known as the maximum distortion strain energy criterion. The von Mises stress, $\sigma_{e}$, is computed with the principal stresses $\left(\sigma_{1}, \sigma_{2}, \sigma_{3}\right)$ as follows:

$$
\sigma_{\mathrm{e}}=\left(\left[\left(\sigma_{1}-\sigma_{2}\right)^{2}+\left(\sigma_{2}-\sigma_{3}\right)^{2}+\left(\sigma_{3}-\sigma_{2}\right)^{2}\right] / 2\right)^{1 / 2}
$$

\section{Critical speed}

The supported bearing stiffness of ceramic bearings used $1 \mathrm{e} 8 \mathrm{~N} / \mathrm{m}$ in simulation. The bending critical speed of rotor should be above operating speed, 200,000 rpm. Fig. 6 shows Campbell diagram. The crossing points are critical speed. The critical speed of 1 st forward whirling of the developed model is $255,777 \mathrm{rpm}$. The separation margin between the operating speed and the bending whirling critical speed needs to be large. An appropriate separation margin is typically $20 \sim 30 \%$ in the bending whirling critical speed [6]. The developed model has $27.88 \%$ separation margin. 


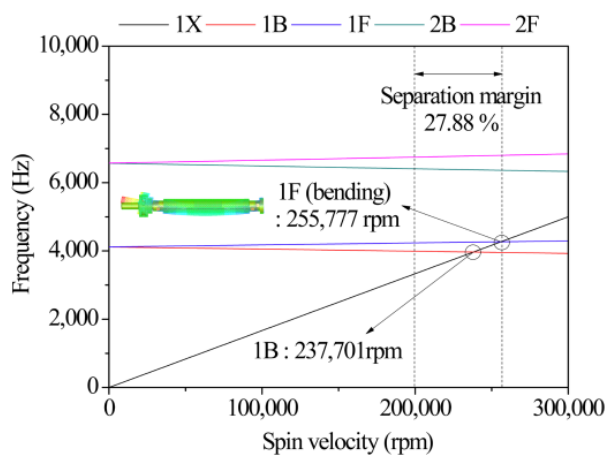

Fig. 6. Campbell diagram (sleeve thickness $=0.8 \mathrm{~mm}$ )

\section{Unbalance analysis}

Table 2. Unbalance (G0.4) and its applied location (sleeve thickness $=0.8 \mathrm{~mm}$ )
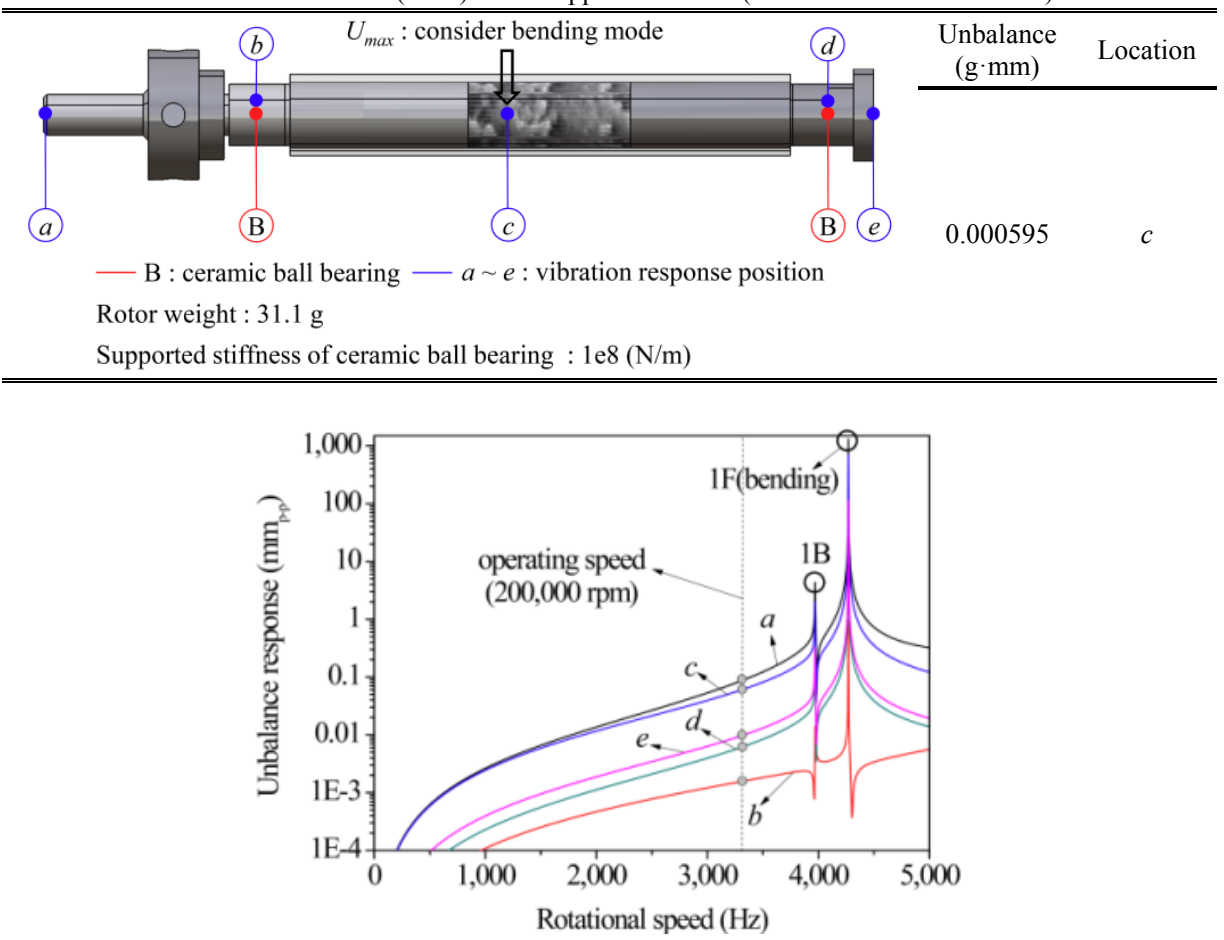

Fig. 7. Unbalance response according to unbalance location and phase (sleeve thickness $=0.8 \mathrm{~mm}, \mathrm{G} 0.4$ )

Unbalance vibration response analysis enable to predict the expected vibration amplitude by unbalance in ultra high speed [5],[6]. Then it needs to check and review rubbing problem between rotor and stator of motor.

The calculated unbalance is like below [5].

$$
\mathrm{U}_{\mathrm{Max}}=9549 \cdot \mathrm{G} \cdot \mathrm{M} / \mathrm{N}(\mathrm{g} \cdot \mathrm{mm})
$$


Where, $\mathrm{G}$ is $\mathrm{G}$ grade, $\mathrm{M}$ is weight of rotor, $\mathrm{N}$ is rotational speed and $\mathrm{U}_{\max }$ is unbalance.

Unbalance magnitude (G0.4) is applied to rotor in this paper. The applied unbalance location and response position to check generated vibration displacement is shown in Table 2. Unbalance response results are shown in Fig. 7 and Table 3 according to unbalance applied location and phase.

Table 3. Vibration displacement result of rotor by unbalance analysis (200,000 rpm, unbalance G 0.4 )

\begin{tabular}{cccccc}
\hline \hline \multirow{2}{*}{ Unbalance model } & \multicolumn{5}{c}{ Location number [vibration displacement $\left.\left(\mu \mathrm{m}_{\mathrm{p}-\mathrm{p}}\right)\right]$} \\
\cline { 2 - 6 } & $a$ & $b$ & $c$ & $d$ & $e$ \\
\hline$c$ & 90.5 & 1.59 & 62.46 & 6.38 & 10.03 \\
\hline \hline
\end{tabular}

\section{Conclusion}

This paper deals with several analyses which need in developing motor-generator which is rated a generator of $800 \mathrm{~W}, 400 \mathrm{krpm}$ and a starter of $400 \mathrm{~W}, 200 \mathrm{krpm}$. This paper is performed loss analysis, structural, thermal-fluid and rotordynamics (critical speed and unbalance) which need in developing the motor-generator. Ultra high speed motorgenerator is well-developed using design, several techniques of analysis and manufacture technique.

\section{References}

1. C. Zwyssig, J. W. Kolar, W. Thaler, and M. Vohrer, "Design of a 100 W, $500000 \mathrm{rpm}$ Permanent-Magnet Generator for Mesoscale Gas Turbines," in Proc. IEEE Ind. Appl. Conf. 2005, Hong Kong, Oct. 2-6, Vol. 1, pp. 253-260, 2005.

2. C. Zwyssig and J. W. Kolar, "Design Considerations and Experimental Results of a 100 W, 500 000 rpm Electrical Generator," J. Micromech. Microeng., Vol. 16, No. 9, pp. 297-302, Sep. 2006.

3. C. Mi, G. R. Slemon, and R. Bonert, "Modeling of Iron Losses of Permanent-Magnet Synchronous Motors," IEEE Trans. on Industry Applications., Vol.39, No.3, pp.734-742, May/June, 2003.

4. D. Miyagi, N. Maeda, Y. Ozeki, K. Miki, and N. Takahashi, "Estimation of Iron Loss in Motor Core with Shrink Fitting Using FEM Analysis," IEEE Trans. Magn., Vol. 45, No. 3, pp. 17041707, March, 2009.

5. ISO 1940-1, Mechanical vibration-balance quality requirement for rotors in a constant (rigid) state, 2003.

6. API Standard 684, Rotordynamic tutorial : lateral critical speeds, unbalance response, stability, train torsionals, and rotor balancing, 2005. 